\title{
CONCEPTUAL DESIGN OF SIGNAL CABLE FEEDTHRUS FOR AN SSC PEOPOSED LIQUID ARGON CALORIMETER*
}

\author{
W. Pope, R. Watt, R. Weidenbach, M. Fong, and D. Bintinger \\ Lawrence Berkeley Laboratory \\ University of Califormia \\ Berkeley, CA 94720 \\ G. Abrams
}

Superconducting Super Collider Laboratory

Dallas, TX 75237

Y. Unno

KEK National Laboratory for High Encrgy Physics

Tsukuba, Ibaraki 303, Japan

3rd Annual International Industrial Symposium on the Super Collider (IISSC)

Atlanta Hilton Towers, Allanta, Georgia

March 13-15, 1991

*This work was supported by the Director, Office of Energy Research, Office of High Energy Nuclear Physics, Division of High Energy Physics, Office of the Superconducting Super Collider of the U.S. Department of Energy, under Contract No. DE-ACO3-76SF00098. 


\title{
CONCEPTUAL DESIGN OF SIGNAL CABIE FEEDTHRUS
}

\section{FOR AN SSC PROPOSED LIQUID ARGON CALORIMETER}

\author{
W. Pope 1 , Y. Unno 3 , R. Watt ${ }^{1}$, R. Weidenbach 1 , \\ M. Fong 1 . G. Abrams 2 , and D. Bintinger ${ }^{1}$, \\ 1 Lawrence Berkeley Laboratory. Berkeley, CA. 94720, \\ 2 Superconducting Super Collider Laboratory, Dallas, Tex. 75237, \\ 3 KEK, Nationad Laboratory for High Energy Physics, Tsukuba, \\ Ibarakj 305, Japan.
}

\begin{abstract}
Fast, low noise readout, high channel counts, and physical space, length, and heat leak constraints on signal cables for Liquid Argon Calorimeters (LAC) for SSC Detectors impose stringent requirements on the performance and reliability of its cryogenic leedthrus. We present the design status of a configuration currently under study for the Solenoidal Detector Collaboration's LAC Detector option. The report includes LAr-to-vacuum leak mitigation, warm cable conduction intercept means, and heat leak estimates for a 1900 pin, hermetic teedtinu plate design.
\end{abstract}

\section{INTRODUCTION}

The Liquid Argon Calorimeter option of the large Detector 1,2 proposed for the Superconducting Super Collider (SSC) by the Solenoidal Detector Collaboration (SDC) consists of a $9.4 \mathrm{~m}$ dia $\times 8.2 \mathrm{~m}$ long, 3100 tonn central Barrel Calorimeter, and two $9.4 \mathrm{~m}$ dia $\times 3 \mathrm{~m}$ long, 1200 tonn Endcap Calorimeters.

The cryostats require about 200,000 penetrations through the LAr vessel walls in the form of cold signal cable feedthru pins.

The Calorimeter's performance requiremen's with respect to hermeticity and depth, coupled with strong economic constraints ${ }^{2}$ on the Detector's overall size impose difficuit trade-offs in the allocation of space and access to individual subsystems. The very limited access to the Barrel Calorimeter including it's gas cooled signal cable feedttin assemblies (SCFT), and the likelihood that some cold pins will leak, in turn, requires that the SCFT design be extremely reliable. It is clear that a means to mitigate pin leakage must be provided, so that cryogenic safety is not compromised.

Early decisions that Barrel cryostat Modules insert irom the ends of the LAr vessel, (and hang on V-block supports attached to the inside of the LAr vessel) and the selected cold mass support means, impose constraints on locations of the SCFT's and options to mitigate their heat leak to the LAr. 
These SCFT locations must be consistent with inner vessel V-block support locations for the outer Hadronic Modules, and provide a direct radial path through the cryostat's thermal protection annulus to incorporate our cold pin leak isolation means. In addition the locations must allow space outside the Cryostat for Calorimeter and Tracker electronics, and provide adequate working space for the subsequent close-out of large numbers of gas, cryogenic fluid, and vacuum circuits (Tracker, Magnet, and Calorimeter).

This report will describe design integration work on the SCFTs for the Barrel and Endcap Calorimeters, and will focus on design features which have been incorporated to deal with the heat loak and provide the necessary operational reliability and safety.

\section{CI)C LAC DETECTOR DESCRIPTION}

Figure 1 is an exploded view of the LAC Detector taken from a recent design integration study 3 . Within the bore of the Barrel Calorimeter is a $4.2 \mathrm{~m}$ O.D. $\times 8 \mathrm{~m}$ long $x=0.35 \mathrm{~m}$ thick, $2 T$ superconducting solenoid. Centra! Tracking chambers for the Detector reside within the Magnet bore. Outside the Calorimeter is the Magnet's octagonal flux return steel, Forward Calorimetry, and an extensive system of iron torroids, tracking chambers and trigger scintillators for muon detection. In this current embodiment of the LAC Detector, there is no access to the region inside the return steel until an Endcap has been withdrawn.

Safety considerations have played a major part in the design of the LAC Detector. Two major concerns are associated with a LAr leak into the experimental hall due to damage to a liquid argon cryostat or to one of the main cryogenic transfer lines.

\section{LAR CALORIMETER AND CRYOSTAT DESCRIPTION}

The SDC's Pb-LAr Calorimeter has been formally described by Unno, et. a 4,5 . The Calorimeter's cryostats have been designed by Kawasaki Heavy Industries (KHI) under the direction of $\mathrm{Y}$. Unno and T. Kondo of KEK. Figure 2, which was recreated at LBL from KHI drawings, will be utilized here to describe those mechanical details of the cryostats which influence the design and location of the SCFTs.

Integration considerations previously described limit the location of the SCFT's to the outer periphery of the cryostats. Cryostat support locations and LAr vessel washers (Figure 2) restrict axial position choices, and Hadronic Module Vblock supports limit $\varnothing$ location options. Locating SCFTs on Endcaps axially (near the LAr vessel supports) is additionally limited, because of "competition" for space at the LAr vessel wall between the internal structural washers and the external LAr vessel support posts (Figure 2).

Because the Endcaps' Main Transfer Line (MTL) junction boxes (to be described later) are best placed at the outboard end, the only choice for the axial location of all Endcap SCFTs is to center them between the LAr vessel's washers (Figure 2), and to avoid them in the LAr vessel support region. Because of this, the outer vacuum cans of these feedthrus are turned 180 degrees from their preferred orientation, with a return-bend in external cabling to their electronics crates. These SCFr locations are more clearly described later in Figures $3 a, 3 b, \& 3 c$. 


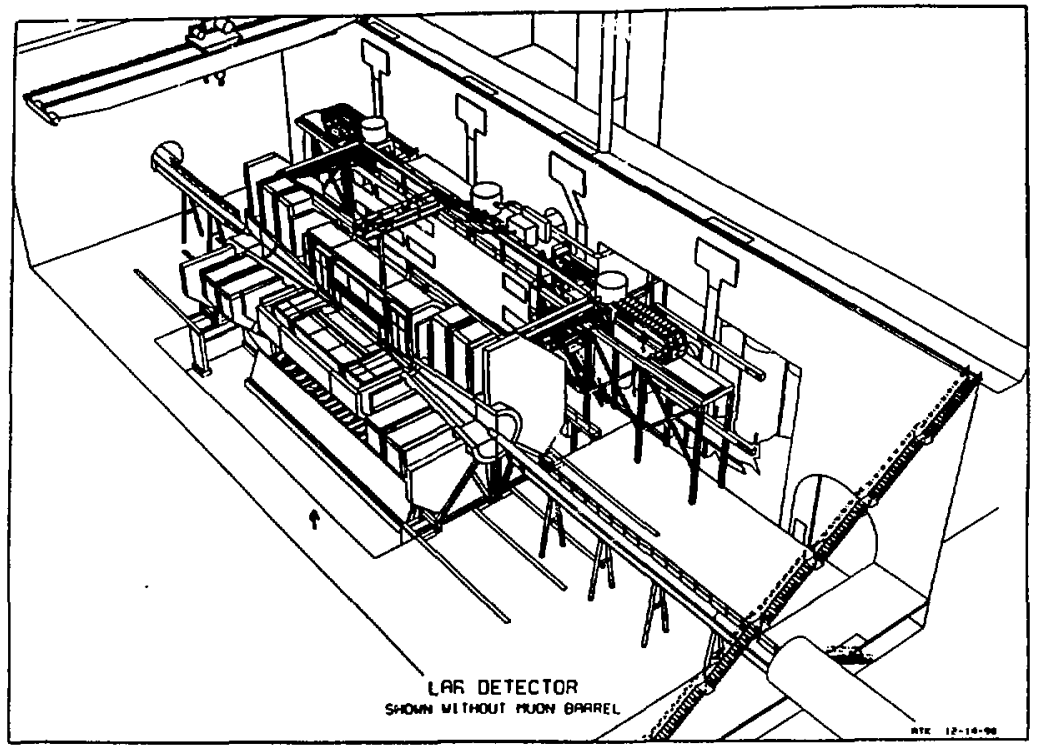

Fig. 1. Details of the SDC's LAC Detector in the underground hall as developed by the SDC Design Integration Team, RTK, and SSCL. The gas cooled signal cable feedthns (not shown) will be placed in the narrow annular region between the octagonal flux return steel and Barrel and Endcap cryostats.

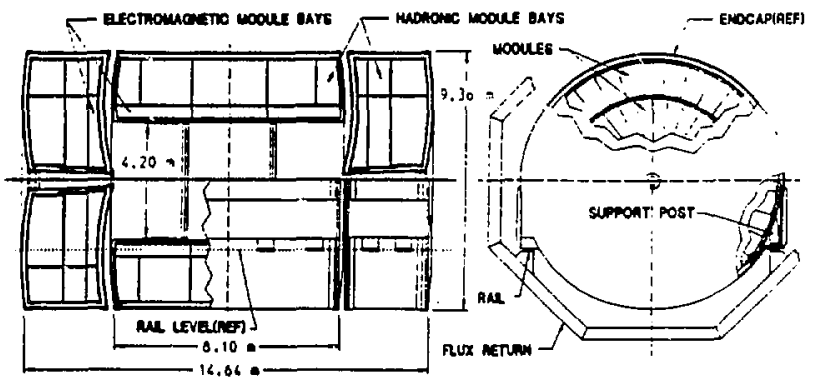

Fig. 2. Simplified representation of the SDC LAC cryostats designed by KEK and Kawasaki Heavy Industries. The Barrel LAr vessel has 8 conduction intercepted, cold mass support "posts"; each Endcap has 4 . The cryostats are supported on rails to the Magnet's steel flux relurn. 


\section{MODULE DESCRIPTION AND CABLE ROUTING}

Unno 5 has also described the Electromagnetic (EM) and Hadronic (HAD) Modules' sizes and tower and stack distributions, so these details will not be repeated here.

The EM and HAD Modules within the Barrel Cryostat are installed from the ends of the vessel onto V-block supports attached to the LAr yessel's shells using a rotatable installation fixture. Signal and HV cables from the Barrel's EM Modules outer strongback region are routed along the length of the Modules to the ends of the LAr yessel (see Figure 2), are then directed radially outward to the outer LAr shell where their end receptacle plugs are attached to pins of hermetic connectors in the Cold Feedthru Plate (CFTP) of the SCFT. The CFTP's must be sulficiently small in diameter to fit in the azimuthal space between V-block supports for Hadronic Modules.

\section{BARREL AND ENDCAP VESSEL EXTERNAL INTERFACE}

Figures 3a, 3b, \& 3c are external views of the Barrel and Endcap Calorimeters with 1) their rings of SCFT's and electronics crates which surround the outer vacuum shells, 2) the 8 large, vacuum insulated MTLs which extend between the Calorimeter vessels and fluid storage tanks and control systems outside the Detector, 3) the 2 Barrel Transfer Line close-out boxes, 4) the Magnet's utilities conduit, 5) the Central Tracker's electronics crates, and 6) the Magnet's octagonal flux retum steel. The retum steel splits near the ends of the Barrel, so that Endcaps can be withdrawn for front-end electronics and Tracker accisss, maintenance, and, if necessary, removal.

The LAC design requires 50.944 signal readout channejs in the Barrel and 21,376 in each Endcap. In this first cut layout of the locations of the SCFTs (Figure $3 a)$, we show 4 rings of 14 feedthrus on the Barrel and a single ring of 23 feecititus around each Endcap. The number of feedthrus is based upon the channel count, and an 850 channel (1900 pin) baseline SCFT design.

The numerous small rectangles (Figure $3 b \& 3 c$ ) represent space for frontend electronics crates (see caption note) which are externally cabled from the SCFTs, whereas the larger rectangles are space which could be used for Tracker electronics and its other local utilities.

The very large, saddle shaped figures at the ends of the Barrel and Endcaps represent MTL-to-cryostat junction regions for vessel-line close-out prior to insertion into the return steel. The 2 each, roughly 36 inch cube shaped features on tubular stand-offs from the Barrel "saddles" are MTL close-out boxes for the Barrel atter it is installed in its return steel.

The SCFTs' non-uniform $\varnothing$ distributions (Figures 3b \& $3 c$ ) result from the space constraints mentioned above, and the need to position these between outer Module V-block supports. Although these $\oslash$ losations for the feedthrus and their electronicr crates around the Barrel are somewhat arbitrary. we provide adequate space to position and access all electronics crates and MTL features.

Direct access to the front side of all electronics crates and 3 sides of the Barrel's MTL close-out boxes is achieved by withdrawing the Endcaps. A 4th side of a close-out box is exposed by simply moving one of the feedthru crates. 


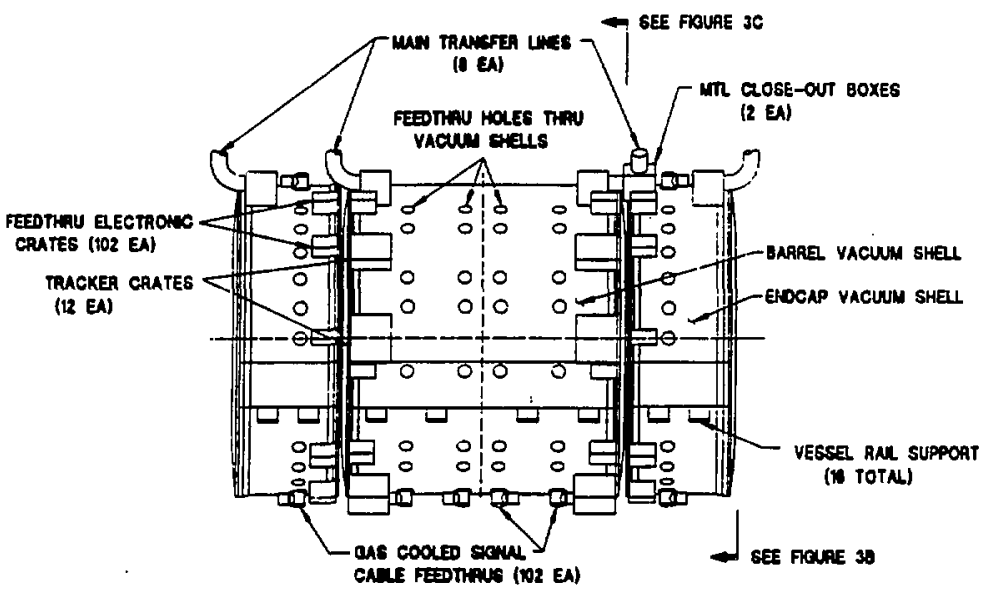

Fig. 3a. Simplified side elevation view of the Barrel and Endcap vessels illustrating selected axial locations for the 102 SCFTs, and their position relationship to other subsystems inside the return steel. See text for details of space and location constraints on the SCFTs and other local subsystems.

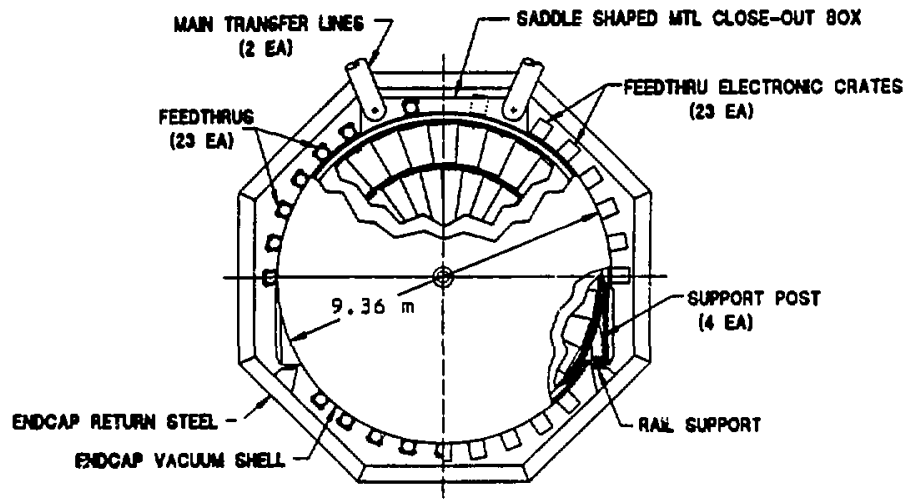

Fig. 3b. Simplifled end elevation of the Endcap illustrating selected $\emptyset$ positions of the 23 SCFTs and their electronics crates. Quantities shown apply for one Endcap. Note: 20 inch high $\times 17$ inch wide $\times 30$ inch long crates we show do not represent standand VME box dimensions. 


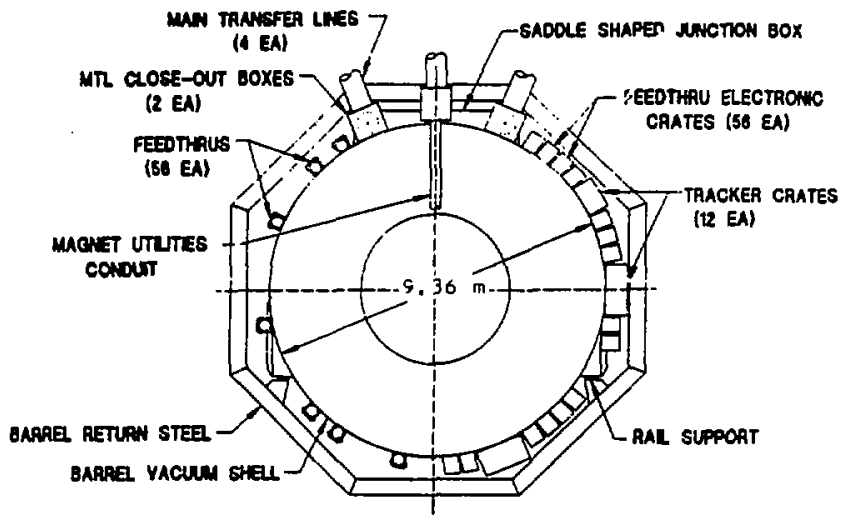

Fig. 3c. End elevation of the Barrel illustrating selected $\varnothing$ positions of its 56 SCFTs (4 rings of 14 each), their electronics crates, and space for Tracker elecimnics crates. Quantities shown apply for the Barrel only. See note in Figure 3b caption. See iext for MTL, junction, and close-out box details.

SIGNAL CABLE READOUT OPTIONS AND SOME CRYOGENIC IMPLICATIONS

The important speed, noise, and pileup performance of the four potential readout schemes considered for the SDC's LAC option have been well documented 5,6 and will only be described in the context of their influence on SCFT parameter selections. A brief description of these four readout types is provided in Table 1.

Table 1 Some characteristics of four LAC readout options. Columns $5 \& 6$ list those influencing heat intercept cable parameter selections.

$\begin{array}{clllcc}\text { Case \# } & \text { Type } & \begin{array}{c}\text { preamp } \\ \text { location }\end{array} & \begin{array}{c}\text { Heat gener- } \\ \text { ated in LAr }\end{array} & \begin{array}{c}\text { Approx. max. } \\ \text { DC resistance } \\ (3)\end{array} & \begin{array}{c}\text { Approx. max } \\ \text { tot. cable length }\end{array} \\ 1 & \text { EST } & \text { inside } & \text { yes } & 10 \Omega & 10 \mathrm{~m} \\ 2 & \text { MT(1) } & \text { Inside } & \text { yes } & 10 \Omega & 10 \mathrm{~m} \\ 3 & \text { EST(2) } & \text { outside } & \text { no } & 1 \Omega & \text { shor (4) } \\ 4 & \text { MT } & \text { outside } & \text { no } & 1 \Omega & \text { short }\end{array}$

(1) Magnetlc transformer readout - Bee relerences $5 \& 6$

(2) Electrostatic transiormer readoul with preamps outside-5ee reterence 6

(3) the maiprity of this resistance is in the SCFT section. Module to teedthu cables are copper.

(4) e.g. no boriger than absolutely necessary. 
Case 2 (magnetic transformer type, with preamps inside the cryostat 5 ) is the current Baseline readout configuration for the SDC's LAC option. It may be noted from Table 1, Case 2 that although cable lengths are limited, the length constraint is much less severe than Cases $3 \&$ \&, and so is the cable's overall DC impedance ${ }^{7--w e}$ can consider, for example, relatively long lengths of small gage, high resistivity wire (e.g. Phosphor Bronze or Stainless Steel) for that portion of the signal cable which operates between $300 \mathrm{~K}$ and about $80 \mathrm{~K}$ in the SCFT.

This allows considerable reduction of the potential heat leak into the cryostat via the signal cables, and opens the possibility of using the limited spent shell coolant gas to intercept this conduction without additional cryogenic circuits. The heat leak reduction is most important to us, because the HAD Modules' V-block supports preclude using a, below the equator, bubble diverting shroud as on other LACs.

\section{PREAMP COOLING}

One of the serious disadvantages of the Baseline readout option (and Case 1) is the extra cryogenic complexity required to remove the heat from the preamps, which are mounted on the Modules in LAr.

Two preamp cooling options are being considired for Case 2. These two options consist of: a) active cooling, with additional 2 phase cryogenic cooling circuits to remove the heat generated at the preamps located near the Modules' outer strongbacks, and b) passive convective cooling.

In the convective cooling option, suggested by R. Richardson of SSCL, the Bariel Module preamps, for example, are surrounded by thermally insulated fluid conduits which extend the length of the Barrel. At the Barrel ends, these conduits hydraulically connect to a lapger main channel which extends around the Barrel ends (below the equatorial plane). The basic concept is to develop a natural convection circulation loop which would take preamp heat gerierated warm liquid and vaper and harmlessly channel it upwards via the insulated conduits to the LAr condensers.

This idea is attractive because it eliminates the need for perhaps 48 active cooling loops inside the LAr vessels, their impact on Transfer Line size, anc their impact on thermal protection system vacuum integnity (see Main Transfer Lines and Calorimeter Cooling below). Each cooling means has been briefly described 8,9 . Further description is beyond the intended scope of this report.

Finally, magnetic shielding of the Ferrite Core Transformers, which is necessary for this readout design, and achievable ${ }^{10}$, will not be discussed here.

\section{GAS COOLED SIGNAL CABLE FEEDTHAU DETAII.S}

The SCFTs are shown in cross-section in Figure 4. The SCFT is designed to virtually eliminate all external cable heat conduction which could cause local boiling within the LAr cryostat, and to provide a high degrze of certainty that moderate connector leakage (e.g. a broken pin) at the Lar vessel wall does not affect the Cryostat's thermal protection vacuum or contaminate the Lar. We feel it is essential to eliminate feedthru conduction to the LAr, because we have no convenient way to divert gas bubbles (no diverter shroud). 
This SCFT, Flgure 4, consists of the following 5 sub-assemblies:

1) the Cold Feedthru Plate (CFTP) assembly,

2) the cold-to-warm wall Transition and Vacuum isolation (TVI) assembly,

3) the Conduction Heat Intercept (CHI) assembly,

4) the warm end feedthru plate, and

5) the Vacuum Box Enclosure (VBE)

The CFTP assembly consists of a relatively thick ( $-1.0 \mathrm{inch}$ ) stainless ste日l plate with a densely packed arrangement (equilateral triangular array) of commercial, welded receptacle flange, hermetic connectors, and a silort, thin stainless steel cylindrical extension (which is field wolded mass spectrometer tight (MST) to the stainless steel plate side of the Al-to-stainless steel transition plate of the TVI during LAr vessel close-out). Local leak checking can be done at each weld as Module installacion proceeds.

The hermetic connectors are currently envisioned as having 22 gauge Gold plated pins with a single glass insert. Existing commercial designs, with leakage specifications of $1 \times 10^{-9}$ Atm-co's at 1 atmospnere, allow as many as 100 such pins per connector with a connector pitch (center-to-center distance) of about 2.07 inch. This permits a compact 1900 pin CFTP with an outer diameter of about 10.6 inch $(270 \mathrm{~mm})$. This 19 connector CFTP is the baseline configuration assumed herein. The maximum operating differential pressure on the CFTP is about 55 psia (the LAr system's nominal maximum operating pressure).

The TVI assembly consists of a commercial Al-to-stainless steel transition plate, a 15 inch $\mathrm{O}$. D. welded-nested-ripple style, stainless steel bellows with a 1.0 inch span (delta-r), and a short aluminum tube which is welded into the LAr vessel's outer Aluminum shell during the cryostat fabrication phase.

This bellows isolates the cryostat's thermal protection system vacuum from SCFT leakage, and aliows the LAr vessel to contract radially and axially the order of 1 inch on cooldown. The bellows is compressed radially inward and retained by a temporary fixture plate after the LAr vessel has been closed-out to facilitate insertion of the LAr vessel into the vacuum vessel.

The CHI assembly consists of a hat shaped, stainless steel inlet section and bolted flange, which is sealed (gas tight only) to the siainless steel side of the Al-10stainless transition plate of the TV! with a cryogenic gasket (either a Kel-F(TM) 0 ring or a commercial metal wire-ring gasket), a curved, thin walled stainless steel cable bundle and gas conduit, a bellows sealed outlet section, and flexible metal coolant gas hoses with commercial fittings (e.g. Varian Conflat(TM), or equivalent).

The curved cable bundle conduit houses the external portion of the 1900 signal cabies (twisted pairs), and provides a compact, parallel array of small hydraulic diameter coolant gas passages to afficiently remove virtually all of the solid conduction down the Teflon(TM) insulated cables.

The warm end feedthru plate is similar to the CFTP, except that cheaper, non-cryogenic, connectors and plugs are used.

The Vacuum Box Enclosure is fabricated from relatively thin walled stainless steel tubing and suitable bolted flanges, and is equipped with a large diameter access flange to tacilitate connecting flanges between the TVI assembly and the $\mathrm{CHI}$ assembly, and final make-up of the internal gas line fittings. Highly reliable rubber O-rings are used to seal all of the other bolted flange joints shown. 


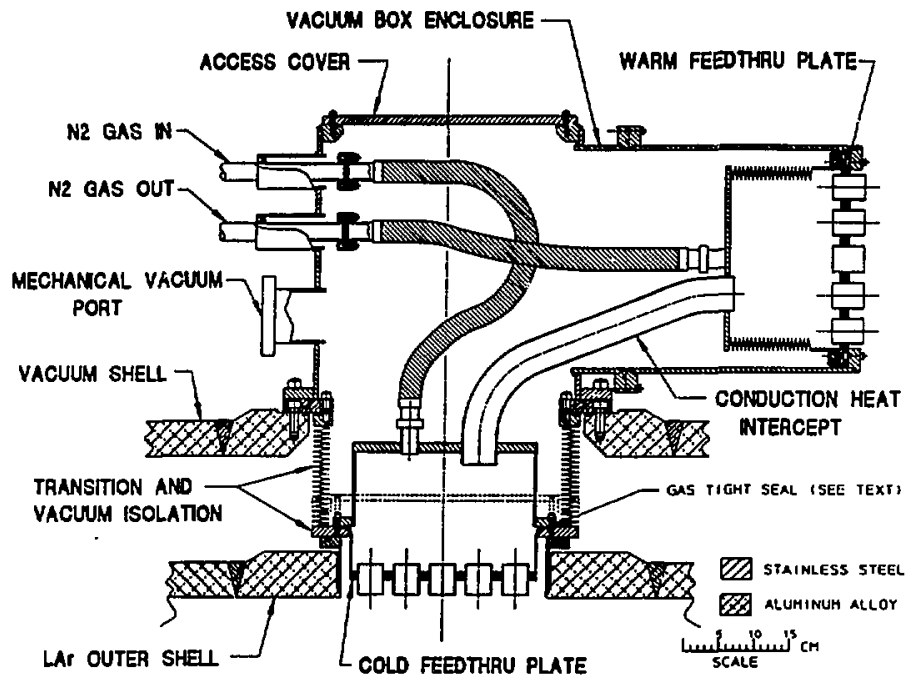

Fig. 4. Details of the gas cooled signal cable feedthru assembly. This design uses high pin density hermetic connectors, an Al-to-St. Stl. transition plate, and St. Stl. bellows, gas lines and fittings--all of high commercial quality. See text for further information.

Table 2 Calculated results of various heat intercept options for 1900 cables per SCFT with $0.178 \mathrm{~mm}$ of Teflon(TM) insulation on each. (Nitrogen gas cooled - Th $=300 \mathrm{~K}, \mathrm{TC}=82 \mathrm{~K}$ )

\begin{tabular}{|c|c|c|c|c|c|c|}
\hline $\begin{array}{l}\text { Wire } \\
\text { matrl }\end{array}$ & $\pi(1)$ & $\begin{array}{l}\text { Equiv. } \\
\text { wire size } \\
\text { (AWG) }\end{array}$ & $\begin{array}{l}\text { wire(4) } \\
\text { length } \\
\text { (cm) }\end{array}$ & $R_{\theta_{i}}(2,3)$ & $\begin{array}{l}\text { cold end } \\
\text { heat leak } \\
(W)\end{array}$ & $\begin{array}{c}\text { mass } \\
\text { flow rate } \\
(\mathrm{g} / \mathrm{s})\end{array}$ \\
\hline $\begin{array}{l}\mathrm{Cu} \\
\mathrm{Cu} \\
\mathrm{PhBr} \\
\text { StSt }\end{array}$ & $\begin{array}{c}90 \\
5 \\
N A \\
N A\end{array}$ & $\begin{array}{c}-30(7 \times 38) \\
-33(3 \times 38) \\
(T B D) \\
(T B D)\end{array}$ & $\begin{array}{l}60 \\
30 \\
30 \\
30\end{array}$ & $\begin{array}{l}80 \\
50 \\
\text { (calc } \\
\text { (calc }\end{array}$ & $\begin{array}{c}0.249 \\
0.066 \\
\text { ons not co } \\
\text { ons not co }\end{array}$ & $\begin{array}{c}0.444 \\
0.242 \\
\text { oleted) } \\
\text { pleted) }\end{array}$ \\
\hline
\end{tabular}

(i) residual reslsthity ratio- $\rho(273 K)^{\prime} \rho(4.2 \mathrm{~K})$

(2) coolant channel's inlet Reynolds number for a "compact" cable bundle

(3) cable twist pitch lgnored in coolant channel characterizations

(4) cooled cable length in the teedthu's heat intercept tube 
Of the 102 SCFT's required, 94 each gre exactly as shown in Figure 4, whereas 8, which are located near the Barrel supports (see Figure 3a), are slightly different. The VDE is somewhat larger on these 8, and the Aluminum adaptor ring has a tubular extension and flange to reach, at a small angle, across the larger vacuum annulus gap.

Conduction Heat Intercept normal operating conditions

Single phase $\mathrm{N}_{2}$ at $-20-25$ psia and a temperature of about 2 to $5 \mathrm{~K}$ below the vessel's local LAr temperature ( -84 to $89 \mathrm{~K}$ ) enters the gas inlet line at the VBE which is maintained below $=0.1$ Torr by mechanical vacuum pumping. The cold $\mathrm{N}_{2}$ gas is routed to the back side of the CFTP and through the CHI assembly where about $98 \%$ or more of the cables' solid conduction heat leak is intercepted as the $\mathrm{N}_{2}$ gas is warmed to about $300 \mathrm{~K}$.

Table 2 lists the expected performance of the Conduction Heat Intercept for various local cable size and material assumptions. Unfortunately, the maximum cable DC resistance constraint was not relaxed to the $10 \mathrm{ohm}$ level until recently. and calculations for Phospicor Bronze and Stainless steel cable (within the SCFT only) have not been completed.

Even though these new cable material options will get the total $\mathrm{N}_{2}$ coolant gas required below about $20 \mathrm{~g} / \mathrm{s}$ (102 SCFTs), which would allow us to consider using a portion of the cold vapor phase of the depleted 2 phase N2 from the LAr vessels' cooling circuits, there is much more to be considered. This is discussed below in the description of the Main Transfer Lines. feedthrus.

A separate, suitably conditioned cold $N_{2}$ gas supply will be provided for the

\section{COLD FEEDTHRU PLATE THEAMAL/STRUCTURAL DESIGN}

Some FEA work using the ANSYS code 11 has been performed on the CFTP of the SCFT. The extent of this FEA work was limited to the determination of the plate thicknesses to achieve low stress levels at the receptacle's weld flange lip for CFTP configurations with high connector packing densities. These simulations assumed we would subsequently adopt CFTP acceptance/qualification test conditions of about 70 psi delta-p at $77 \mathrm{~K}$ with mass spectrometer tight leakage requirements. In this FEA work, the receptacle stiffness was simulated using the dimensions of a "typical" commercial receptacle body (also stainiess steel), and a single solid glass insert (no pins). We have discussed our connector requirements with major hermetic seal vendors, and have received proposed designs.

\section{MAIN TRANSFER LINES AND CALOFIMETER COOLING}

The large, -18 to 24 inch diameter vacuum insulated, MTLs previously mentioned are common with and provide the evacuation channels for the Barrel and Endcap thermal protection systems. Each MTL contains several fluid circuits.

Within the vacuum jackets of the for ' MTLs for the Barrei, ior example, there are: a) 10 ea, 2 phase $\mathrm{N}_{2}$ circuits to cool dewn and control the fluid state within the LAr vessel, b) thio LAr vessel's fill, fill-vent, and liquid withdrawal lines, and c), if active preamp cooling is used, perhaps 16 each, 2 phase $\mathrm{N}_{2}$ or Ar circuits. 
Within the two MTLs on each Endcap there are: a) 4 ea, 2 phase $\mathrm{N}_{2}$ circuits to cool down and control the fluid state within the LAr vessel, b) che 2 phase $N_{2}$. circuit to intercept support post contuction, c) the LAr vessei's rill, fill-vent, and liquid withdrawal lines, and d), if active preamp cooling is used, anoiher 16 each, 2 phase N2 ur Ar circuits.

Decisions regarding the location of and egress thru the Detector for the Ba*rel LAr 'vessel's support post cooling circuit have not been finalized, and consequently, are not shown. This $N_{2}$ circuit need not be within the Barrel's MTLs (and thus further impacting their size), because the Barrel is stationary.

The 8 larga MTLs make several berids (see Figure 1) between the Calorimeters and external tankage, and will require numerous internal flexible sections. These flexible sections will be constructed with double walled stainless steel hose for leakage protection. Leak checking means will be provided to isolate Transfer Line hose leaks from leaks within cryostat vacuum shells. This "isolation capability" at individual hose sections is important to minimize lost time and confusion during initial cryostat-to-external piping clese-out operations.

With the exception of the common vacuum shargd by the Miain Transfer Lines and thermal protection systems of the Calorimeters' vessels, cryogenic cooling, conditioning, and control of the LAr state within ihs SDC LAC vessais is generically quite similar to the system successfuliy developed by Barrera and Watt for SLD 12 .

\section{DISCUSSION OF THE SCFTS MAJOR REQUIREMIENTS}

In the introduction and in subsequent detail descriptions, reference was made to the need for the SCFT design to provide the $300 \mathrm{~K}$ to $85 \mathrm{~K}$ transition across the cryo:itat's thermal protrsction syste!n boundaries without causing boiling of LAr within the Calorimeter, and the importance of doing this without compromising the Detector's operational reliability and safety.

Careful inspection of the SCFT design, Figure 4, reveals that with a gas inlet temperature berow that of the local LAr on the opposite side of the CFTP, virtually rione of the extemal cable heat leak can cause boiling within the LAr vessel. In addition, the small amount of solid conduction through the stainless steel vacuum isiolation bellows of the TVI can be easily removed by the 2 phase $\mathrm{N}_{2}$ cooling circuits welded to the outsidu of the thick, Aluminum alloy LAr vessel (as in SLD) if the axial thermal conductance of the shor Aluminum tibe of the TVI is relatively large, and it's mean temperature is maintained below the local LAr temperative.

Inspection of Figure 4 will also show that moderate amounis of pin leakage will have no affect on the Cryostat's (and MTL) thermal protection system vacuum unless the vacuum isolation bellows (which operates with a negligible differential pressure) fails. This possible failure mode can be easily avoided with proper design by selecting a commercial bellows o! suitable flexibiity with a conservative number of convolutions for the known travel requirements.

Finally, these SCFTs have been su'scessfully integrated with the cryostats designed by KEK and Kawasaki Heavy Industries, and all other LAC subsystems competing for the limited space within the return steel. This "integration" was identified as a critical issue for the LAC Detector option in our Letter of Intent ${ }^{2}$. The required level of access ${ }^{3}$ has been obtained. 


\section{CONCLUSIONS}

A SCFT has been describod for the LAC Detector option proposed for SSC by the Solenoidal Detector Collaboration. These units provide all the known Detector objectives for this service, with no known compromise to the high safety and reliability requirements which we feel will be necessarily imposed by SSCL management for operation of such a facility.

\section{ACKNOWLEDGEMENT}

We thank J. Rasson and Y. Minamihara for their assistance in the integration of the Calorimeter vessels with other Detector subsystems. The convenient Transfer Line junction and close-out boxes are a creation of F. Barrera, formerly of SLAC. We thank J. Siegrist and C. Hearty for their leadership in the LAC Detector option and for their review of this report. We especially thank R. Richardson (SSCL) for his help on preamp cooling, and in our general efforts to finalize the LAC's cryogenic systems in a safe, reliable manner.

This work was supported by the Director, Office of Energy Research, Office of High Energy Nuclear Physics, Division of High Energy Physics, Otfice of the Superconducting Super Collider of the U.S. Department of Energy, under Contract No. DE-ACO3-76SF00098.

\section{REFERENCES}

1. G. H. Trilling et al., "Solenoidal Detector Collaboration Expression of Interest". SSC-EOIO003 (1990).

2. G. H. Trilling et al., "Solenoidal Detector Collaboration Letter of Intent", SSC-LOIOOO1 (1990).

3. M. Riddle et a' "A Design Study of Interaction Halls and Assembly

Procedures for a Solenoidal Detector at the SSC", (RTK, LBL, \& SSCL), SSC-SR-1152 (1991).

4. Y. Unno et al., "Design of a Liquis Argon Calonimeter for SDC", in Proc. of the JSD Workshop at KEK, 1990, and subsequent updates.

5. Y. Unno, "Speed and Noise", in Proc. of the JSD Workshop at KEK. (1990).

6. C. Hearty et al., "Llquid Argon Calorimeter Readout with an Electrostatic Transformer and External Preamps", in Proc. of the Fort Worth Symposium on Detector R\&D for the SSC (to be published) (1990).

7. C. Hearty, private communication with W. Pope 2/26/91.

8. R. Watt, a series of informal presentations at SDC LAC tele-conferences (Sept 1990.Mar 1991) on preamp active cooling options.(unpublished).

9. R. Richardson, a stries of informal presentations at SDC LAC teleconferences (Jan-Mar 1991) of developing preamp convective cooling ideas. (unpublished).

10. I. Honath et al., "Magnetic Transformers for the SDC," submitted to the SSC Lab., SDC-90-00069 (1990).

11. ANSYS, Swanson Analysis Systems, Inc.

12. M. Bitedenbach ef al., "SLD Design Report", SLD Collaboration, SLAC Report No. 0273. 